\title{
A importância das TICs na logística de defesa: estudo de caso sobre a Guerra do Golfo (1991)
}

\author{
The importance of ICTs in defence logistics: \\ the Gulf War (1991) case study
}

Rev. Bra. Est. Def. v. 3, nº 2, jul./dez. 2016, p. 119-137

ISSN 2358-3932

\section{ANA LAÍSE FERREIRA HERCULANO BATISTA ANTONIO HENRIQUE LUCENA SILVA}

\section{INTRODUÇÃO}

Por falta de um prego, o sapato estava perdido; Por falta de um sapato, o cavalo foi perdido; Por falta de um cavalo, o cavaleiro estava perdido; Por falta de um cavaleiro, a batalha foi perdida (Franklin apud Kress 2002, 8). ${ }^{1}$

Assim como para Napoleão Bonaparte "o exército marcha em seu estômago" (apud Kane 2001), ${ }^{2}$ Frederick the Great "considera que [...] a formação do exército é a barriga" (apud Kane 2001). ${ }^{3}$ Verifica-se, no entanto, que sob a perspetiva desses bravos guerreiros, a logística de defesa sendo analiticamente aludida ao estômago ou barriga de seus exércitos corresponde a dizer que a logística se trata de uma parte imprescindível aos exércitos, isto é, a parte central de qualquer operação militar.

Ana Laíse Ferreira Herculano Batista - Mestra em Ciências Militares pelo Programa de Pós-Graduação em Ciências Militares (PPGCM) do Instituto Meira Mattos da Escola de Comando e Estado-Maior do Exército (IMM/ECEME) e Bacharel em Relações Internacionais. Pesquisadora no Laboratório de Segurança Internacional e Defesa Nacional da Escola Superior de Guerra (LABSDEN - ESG).E-mail: analaisefhb@hotmail.co.uk.

Antonio Henrique Lucena Silva - Doutor em Ciência Política pela Universidade Federal Fluminense (UFF). Mestre em Ciência Política pela Universidade Federal de Pernambuco (UFPE). Licenciado em Ciências Sociais pela UFPE. Docente da Faculdade Damas da Instrução Cristã e da Faculdade Estácio do Recife. Pesquisador do Instituto de Estudos Estratégicos da UFF e membro do GEESI-UFPB. E-mail: antoniohenriquels@gmail.com.

Esse texto foi desenvolvido a partir do trabalho da disciplina Logística de Defesa, do Instituto Meira Mattos, da Escola de Comando e Estado-Maior do Exército (IMM/ECEME), ministrada pelo Professor Dr. Luiz Rogério Franco Goldoni e Prof ${ }^{a}$. Ariela Diniz Cordeiro Leske. 
Visto desta forma, é notável que se deva uma maior atenção ao tema, pois se a logística de defesa é o fator condicionante a consecução da guerra, da mesma forma a logística deve ser considerada o fator determinante ao seu triunfo.

Apesar da importância supracitada, a logística de defesa não se apresenta de fácil realização, pois para o seu desenrolar, seja na guerra, em operações humanitárias ou até mesmo em operações de paz, encontramos obstáculos característicos desses ambientes como as vulnerabilidades e as incertezas. Logo, cientes dessas peculiaridades, observamos que, mesmo com o passar dos anos, as dificuldades inerentes ao teatro das operações permanecem. Desta forma, as atividades de logística de defesa no ambiente do pós-Guerra Fria apresentaram novos rumos e um maior grau de complexidade, no momento em que o envolvimento de novos atores (ONGs, empresas privadas, etc.) em operações militares aumentavam, bem como na abrangência do envolvimento militar em uma ampla gama de missões.

Não obstante, há de se mencionar a implicação do uso da Tecnologia da Informação e Comunicação (TIC), tanto nas ferramentas (armas, transporte, etc.) utilizadas pelas Forças Armadas (FA ou FFAA), quanto na capacidade das TICs em oferecer um melhor desempenho na logística militar, uma vez que a obtenção de informações em tempo real, via satélite, permitiu à era da logística se basear em prazos.

De modo a entender o papel das TICs na Logística de Defesa, este trabalho irá procurar levantar alguns pontos relevantes ao tema. Logo, o artigo está estruturado da seguinte forma: a) explorar as diferentes definições sobre o que vem a ser a logística, logística de defesa e logística militar; b) conhecer quais os níveis que perpassam a logística militar, bem como entender porque e como suas atividades se correlacionam; c) compreender os desafios enfrentados pela logística militar, assim também como d) a importância das TICs para consecução da atividade logística; e por fim, e) analisar a implicação do uso das TICs no estudo de caso da Guerra do Golfo (1991).

A escolha da Guerra do Golfo (1991) como estudo de caso desse artigo adota o ponto de vista das Relações Internacionais (RI), em que se preze o reconhecimento da guerra como um marco que inaugurou de maneira incisiva o período pós-Guerra Fria (Alves, 2010), tratar-se também de uma das primeiras guerras com o uso das armas tecnológicas, aqui entendido pelo uso de: satélites, computadores, mísseis balísticos (por terem sido utilizados na Guerra do Golfo) e meios de comunicação social - que demonstrou maior eficácia e capacidade logística estratégica para o alcance da vitória na guerra.

Para a realização desse trabalho, utilizamos na pesquisa a análise de documentos e artigos correlacionados ao tema, arquivos e trabalhos disponíveis em sites de universidades e núcleos, centro de pesquisas de estudos 
voltadas para área de defesa, bem como fontes governamentais que dessem embasamento e trouxessem evidências para a elaboração da avaliação das TICs no conflito.

\section{LOGÍSTICA EMPRESARIAL, DEFESA E LOGÍSTICA MILITAR}

Embora o termo logística seja uma expressão moderna, é uma palavra por vezes associada por alguns autores ao termo grego logistikos (hábil para fazer cálculos), ou ainda, do latim logista (um romano ou administrador bizantino), no qual ambas as palavras expressam o uso da matemática, cálculos ou assuntos não militares, esse último por sua vez, surge no final do século 18 ou início do século 19 (Thorpe’s, 1986, XVII). Todavia, a logística como a conhecemos hoje, é popularmente utilizada em razão da área empresarial como

[...] um processo de planejamento, implementação e controle do fluxo de maneira eficiente, efetiva o fluxo da armazenagem de produtos, bem como os serviços e informações associados, desde o ponto de origem até o ponto de consumo, com o objetivo de atender às exigências do consumidor (Council of Supply Chain Management Professionals - CLMP ${ }^{4}$ 2015). ${ }^{5}$

De acordo com a citação do Council of Logistics Management Profesionals (CLMP), a logística empresarial não somente visa a competitividade, mas a redução do custo e sobretudo a lucratividade das empresas.

Contudo, em um ramo menos difuso porém dicionarizado a respeito da logística, observa-se a seguinte menção: "o ramo da ciência militar que trata da aquisição, manutenção e transporte de material, pessoal e instalações” (Webster 1993 apud Ballou 2004, 27). No contexto logístico militar supracitado, nos remete a uma atividade muito mais antiga do que a decorrente do efeito da globalização abordada pela CLMP, pois é nos primórdios das guerras que se pode observar os primeiros agrupamentos humanos em conflito, a utilização de armas, a necessidade de locomoção, de proteção e de alimentação (Brick 2011).

Empregada de maneira mais incisiva pelo barão suíço Antoine Henry Jomini, logística é "a arte de movimentar exércitos. Compreende a ordem e detalhes das marchas e acampamentos, e de caserna e fornecimento de tropas; em suma, é a execução estratégica e tática das empresas" (Jomini 2005, 4). ${ }^{6}$ Desta forma, Jomini estabelece a logística como uma das cinco ferramentas para condução da guerra, ${ }^{7}$ compreendendo todos os meios e arranjos que sustentam a estratégia e a tática, e, assim, relacionada a todos os aspectos de uma campanha militar (Brick 2011). 
Por sua vez, segundo o professor de pesquisas operacionais da Naval Postgraduate School (NPS), Moshe Kress, trata-se de "uma entidade multidimensional e complexa que constitui um dos componentes mais importantes e essenciais da guerra" (Kress 2002, 2). ${ }^{8}$ Em contrapartida, para o manual de logística do Exército Brasileiro (Estado-Maior do Exército 2014, 15), o termo logístico é: "o conjunto de atividades relativas à previsão e à provisão dos recursos e dos serviços necessários à execução das missões das Forças Armadas”.

Ainda que a logística seja entendida, de forma geral, como provimento de meios (alimentos, energia, etc.) para atender às necessidades, sejam estas de clientes ou uma operação militar, as diferentes definições apresentadas são de alguma forma complementares, pois o termo logístico é de difícil delimitação, uma vez que aborda diferentes esferas, desde entidades até processos e regras (Kress 2002), variando amplamente entre as Forças Armadas dos países, seus ramos de trabalho (Kane 2001), assim também como por pesquisadores e entusiastas em diferentes épocas e tempo.

Apesar disso, quando transcrita para o exercício no teatro de operações de guerra ou paz, a logística militar deve ser entendida como parte do 'processo produtivo' da logística no âmbito da defesa, onde o "provimento de meios para compor as Forças Armadas e sustentar suas operações em quaisquer situações em que elas tenham que ser empregadas” (Brick 2011, 6). Assim, a logística militar é um dos elementos cruciais à contribuição e ao sucesso de qualquer missão militar (humanitária, guerra ou operações de paz), ajudando a decidir o curso e os resultados da guerra como parte de um arcabouço estratégico, vista a movimentar, fornecer e manter as Forças Armadas (Kane 2001, 17).

Desta forma, pressupõe-se que a logística militar é um processo que perpassa pela cadeia de suprimentos, da obtenção de sua matéria-prima ao consumo do produto final, fornecimento de material bélico, medicamentos e sua estocagem, movimentação de tropas, entre outros (Silva e Musetti 2003). Portanto, é necessário que as atividades logísticas sejam coerentemente planejadas e executadas também em tempo de paz (Estado-Maior do Exército 2014). Isso posto, a logística torna-se um fator decisivo à estratégia no campo das operações militares, como uma atividade integradora, logo, reconhecida como obtenção de poder de combate (Kane 2001, 17).

No entanto, o que muitos desconhecem é a correlação existente entre o preparo do gerenciamento econômico e a logística (vide a seguir a Figura 1 - Correlação Economia X Logística), pois a economia acaba por impactar diretamente na capacidade de resposta, desenvoltura, versatilidade, improvisação e inovação (Kane 2001). 
Segundo a ilustração, podemos observar a forte relação imposta pela restrição econômica à logística e, assim, a toda uma rede de componentes voltados a sua capacidade, como um grande 'efeito dominó' que acaba por comprometer as demais redes logísticas.

As capacidades por sua vez, expõem as características intrínsecas ao papel da logística na defesa, tais quais como: proteger e defender o interesse público e a segurança do Estado a longo prazo (Yoho et al. 2013).

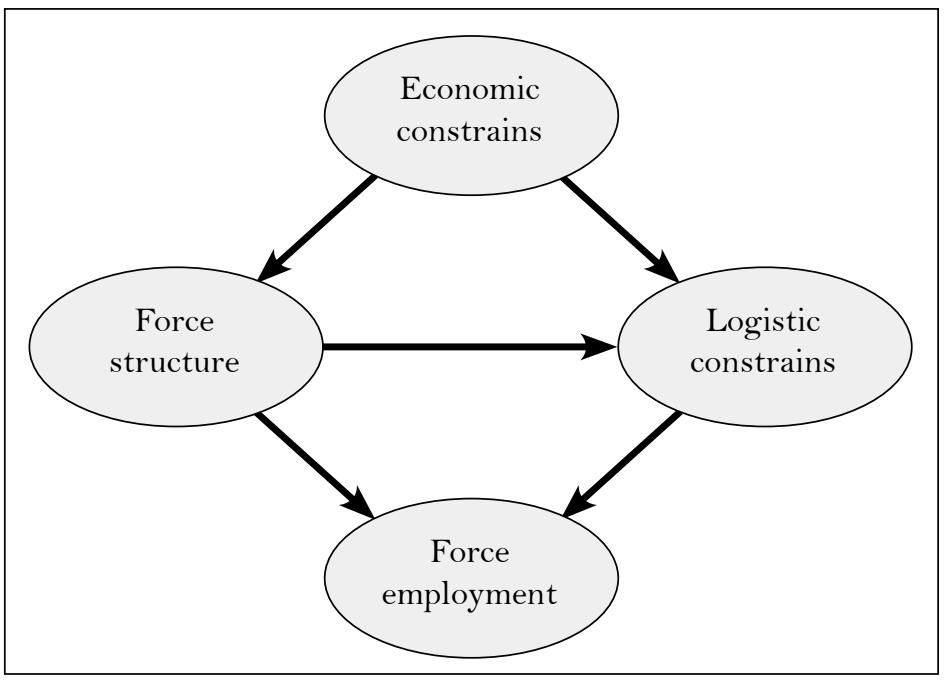

Figura 1 - Correlação Economia X Logística.

Fonte: Kress (2002, 20).

\section{NÍVEIS DA LOGÍSTICA}

De acordo com Kress (2002), na guerra são três os níveis que pertencem à logística militar: a) a estratégica; b) a operacional; e c) a tática. Ainda para Kress, esses níveis não estão necessariamente separados ou difusos, pois como visto na Figura 2 a seguir (Níveis da Logística Militar), suas áreas funcionais se intersectam em algum momento.

Os quadros mostram que o nivel estratégico (conhecimento de planos militares e intenções) empregará e determinará dentro da estrutura político-militar os objetivos e a orientação nacional ou multinacional, assim como o emprego dos recursos nacionais para o alcance dos objetivos; a nível operacional, portanto, encontra-se o planejamento e a condução das operações, com base na estratégia designada; enfim, é no nível tático (vigilância 
militar de capacidades e atividade) que se encontra o uso das unidades de combate, como: reabastecimento em geral (munição, alimentação, etc.); fixação de equipamentos; fornecimento de rações entre outros produtos de necessidades pessoais; ajuda médica imediata e evacuação do local; tratamento dos prisioneiros de guerra; e da população civil (Kress 2002).

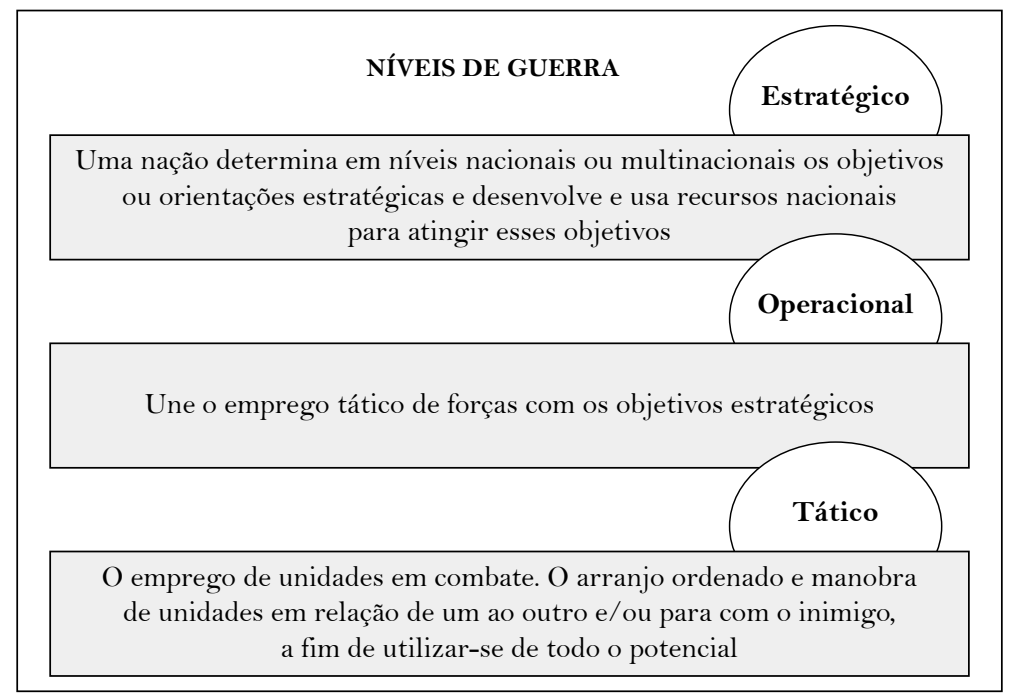

Figura 2 - Níveis da logística militar.

Fonte: Marquardt $(1999,6)$.

Visto as correlações dos níveis logísticos com o nível da guerra, o próximo quadro (vide Figura 3 - Atividades dos Níveis Logísticos) busca especificar as suas mais diversas atividades.

A Figura 3 procura consolidar a forma como todos os níveis e networks dependem e precisam da logística. Ainda de acordo com a figura, para que o exército possa operar de forma a conduzir toda uma tropa, é necessário que a logística, doutrina em nível operacional, forneça às FA os princípios que possam ser aplicados e adaptáveis às diferentes atividades e situações.

Não obstante, visto a interdependência entre os níveis e networks logísticos, acredita-se que com o impacto da Tecnologia da Informação e Comunicação (TICs), os sistemas logísticos de integrarão e os três níveis (estratégico, operacional e táticos) têm grande propensão a fundir-se (Kress 2002). 


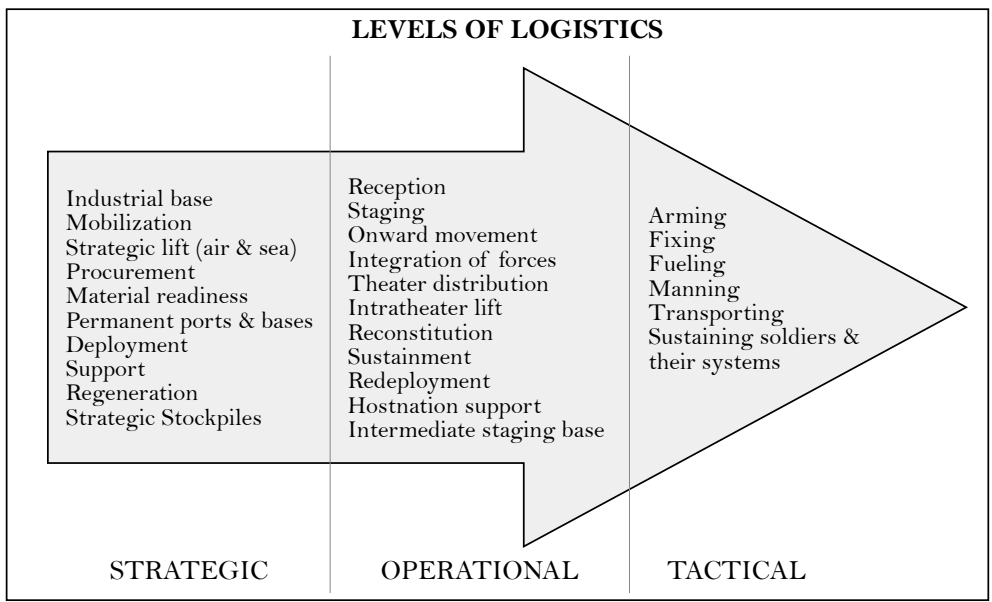

Figura 3 - Atividades dos Níveis Logísticos.

Fonte: Marquardt (1999, 9).

\section{DESAFIOS À LOGÍSTICA MILITAR}

Assim como a logística se faz fundamental para a execução dos níveis na condução da guerra (estratégia, operacional e tática), como: meio facilitador da movimentação de fogo; evacuação; implantação de recursos; posição humana (Kress 2002); coordenação civil direcionadas para o esforço bélico; emprego das FA nas atividades administrativas dos ciclos de mobilização, ${ }^{9}$ guerra e desmobilização ${ }^{10}$ (Silva e Musetti 2003). Do mesmo modo, as atividades competentes à logística se fazem desafiadoras e de difícil desenvoltura, pois os ambientes de campo de batalha e de operações de desastres se apresentam como dinâmico (interagências), incerto e, portanto, vulnerável (Yoho et al. 2013), ademais, trata-se de um ambiente sujeito as hostilidades do inimigo e aos elementos do teatro da guerra (Kress 2002).

Outrossim, é reconhecível por parte de órgãos de governo voltados para Logística de Defesa ${ }^{11}$ que "as demandas de logística expedicionárias são muito diferentes das que prevaleceram na Guerra Fria” (The National Audit - NAO ${ }^{12} 2003$ e Mark 2004, 30). ${ }^{13}$ Isso significa dizer que, se na Primeira e Segunda Guerra Mundial (de 1914 a 1945) a logística militar se restringiu a suprir e transportar (homens, animais, alimento, munição e equipamentos) num claro ato de esforço de guerra, assim como vistas a mobilização industrial em larga escala (Silva e Musetti 2003, 346). O pós-Guerra Fria, por sua vez, atribuiu novos desafios militares, o que con- 
sequentemente fomentou a necessidade de desenvolvimento do suporte logístico para as novas demandas enfrentadas nas operações militares (Fox 2008).

Dentre as demandas decorrentes das mudanças do fim da Guerra Fria (1990), no que tange a transição de um mundo bipolar para o unimultipolar, observa-se que: 1) novas e eficazes armas de fogo demandavam maiores gastos financeiros em munição, logo, um aumento no meio logístico para alimentação do Input de fornecimento (relação economia $\mathrm{X}$ logística); 2) a substituição de cavalos por um exército mecanizado e motorizado traduz-se em uma grande quantidade de combustível e manutenção sobre os estoques de peças e ferramentas para fins especiais, bem como uma maior disponibilização dos instrumentos; 3) o desenvolvimento da medicina, com melhores tratamentos, exigiria que unidades de apoio médico fossem distribuídos e bem localizados; 4) assim como para atender a remodelagem de tanques, veículos blindados e aeronaves se fazia necessário incluir linhas terrestres de comunicação e meios de transporte (Kress 2002).

Deve-se ressalvar que o pós-Guerra Fria proporcionou a ascensão de novos atores internacionais (civis, ONGs, entre outros) que, por ventura, acabam por desempenhar um papel cada vez mais relevante na consecução das operações militares em momentos de guerra ou não (Yoho et al. 2013), onde se faz notável que boa parte das atividades na área de logística de defesa são empregadas pelo setor público, privado e/ou pela terceirização com o suporte de subempreiteiros de modo a complementar tarefas de apoio logístico às FA (Yoho et al., 2013, inter alia, Silva e Musetti 2003, 348).

As consequências das remodelagens logísticas, para atender os inevitáveis desafios impostos pela economia global, tiveram implicações consideráveis na forma como a guerra é conduzida. Não obstante, observou-se que as estratégias até então empregadas no mundo também sofreriam alterações significativas (Fox 2008). Pois assim como a globalização impactou patamares referentes à logística, também foi possível notar transformações significativas no plano logístico estratégico-militar (Kress 2002).

Apesar das explícitas mudanças na condução da logística estratégica, em que os objetivos na esfera militar exprimi-se na vitória ou sobrevivência da nação, e a empresarial no lucro, é reconhecível que, no âmbito da tomada de decisões ambas não diferem muito, uma vez que essas são tomadas em níveis de conselhos administrais. Contudo, no âmbito da defesa, os desafios sofrem impacto a longo termo, o que implica economicamente em investimentos em pesquisa e desenvolvimento (P\&D), renovação de políticas e assuntos sobre infraestrutura física (Kress 2002). 


\section{A IMPORTÂNCIA DAS TICS NA LOGÍSTICA MILITAR}

Vivemos numa era comandada pela informação. Descobertas tecnológicas [...] estão alterando a face da guerra e a maneira como nos preparamos para enfrentá-la (Perry apud Nunes, 1999).

Assim como ao desenvolvimento de qualquer Estado moderno, as TICs têm e vêm desempenhando um papel de fundamental importância na área da logística, e em particular na logística militar, a fim de sustentar os objetivos das operações e suas estratégias (Lamus 2015). Esse último, por sua vez, busca focar sua preocupação na construção, manutenção e/ou infraestrutura militar, onde, em relação a esse último ponto são apontados cinco itens à sua composição: indústria, estoque, armazenamento, transporte $\mathrm{e}$ tecnologia (Kress 2002).

No que diz respeito ao desempenho das TICs na logística e mobilização militar constata-se a importância do gerenciamento das informações de forma eficaz e rápida, permitindo o cumprimento do dever, no menor tempo possível, e na capacitação dos integrantes das FA, com a finalidade de consolidar a informação no lugar e no momento requerido (Lamus 2015).

Deste modo, mesmo que os problemas das grandes guerras ainda persistam, como processo de planejamento, alinhamento e sincronização de logística com planos operacionais; previsão, programação, controle de estoque e sua distribuição no teatro da guerra; reabastecimento tanto na superfície (terra) quanto no mar; questões de armazenagem; coordenação das relações entre os atores civis-militares entre outros (Yoho et al. 2013), cabe à Base Logística de Defesa (BLD), "agregado de capacitações, tecnológicas, materiais e humanas, necessário para desenvolver e sustentar a expressão militar do poder, mas também profundamente envolvido no desenvolvimento da capacidade e competitividade industrial do país como um todo", procurar sanar as implicações tecnológicas à logística (Brick 2011,6).

Dado que a infraestrutura da BLD está centralizada na "capacidade educacional, científico-tecnológica e industrial, capaz de gerar inovações e suprir as demandas de recursos de toda ordem para o sistema de defesa" (Brick 2011,7), por consequência, recai sob infraestrutura tecnológica os demais aparatos da logística, pois é em seus recursos que se desenvolve, melhora, mantêm e se alimenta os demais sistemas (Kress 2002) e de maneira mais significativa, agindo na obtenção das tropas e equipamentos no lugar certo e na hora precisa (Fox 2008). 
A relevância do uso das TICs na logística de militar, se faz ainda mais clara quando as novas condições e dinâmicas se fazem mais presentes nas operações do século XXI: o aumento da complexidade e custos de novas armas e seus sistemas; aumento de operações conjuntas (entre os elementos armados das nações e países aliados); aumento do papel militar em operações e assistência humanitária, bem como a desastres; manutenção e revisão de sistema de armas e sua defasagem; e, por último, porém não menos importante, os reajustes logísticos necessários à crescente demanda da guerra da informação ${ }^{14}$ (Yoho et al. 2013).

Logo, o uso das TICs compreende a uma ferramenta fundamental em nível de planejamento e pensamento estratégico contemporâneo (Duarte 2012, 10, inter alia; Nunes 2000), pois é no século XXI que essa tecnologia encontra sua maior expressão como uma arma ofensiva do moderno campo de batalha e como uma arma de "ataque logístico" (Nunes 2000).

Esta concepção fortalece a questão envolta sobre como a rapidez, tecnologia e economia afetam diretamente no sucesso ou não dos problemas e formulações, bem como das decisões a serem tomadas de forma a sanar os desafios que ainda prevalecem (Kress 2002).

\section{BREVE PANORAMA DA GUERRA DO GOLFO (1991) E SUA ARTICULAÇÃO LOGÍSTICA ESTRATÉGICA}

A tecnologia que prevalece no contexto histórico que segue o pós-Guerra Fria é a mesma que emerge como elemento desafiador e indispensável a um bom funcionamento logístico (Fox 2008). A guerra do Golfo (1991) demonstrou a capacidade das TICs em vencer as barreiras logísticas, pois, mostrou-se como um dos maiores conflitos militares convencionais desde a última metade do século XX e a maior dos últimos vinte anos, cujo conflito envolveu mais de trinta países, bem como todo aparato militar convencional moderno disponível (Alves 2010).

A guerra no Golfo Pérsico ocorreu com a invasão do Iraque ao Kuwait, por questões comerciais petrolíferas. De um lado o Iraque alegava que o petróleo estaria sendo retirado pelo Kuwait além do acordado pela Organização dos Países Exportadores de Petróleo (Opep), e que estaria sendo vendido além do permitido no open market, fragilizando, assim, o comércio de petróleo no Iraque. Além disso, o governo iraquiano de Saddam Hussein também reivindicava o território da província de Basra, até então pertencente ao Kuwait. Segundo Hussein, este território pertencera ao Iraque no passado (Moore et al. s/d).

O pico da invasão do Iraque ao Kuwait ocorreu quando o Kuwait se negou a pagar uma compensação milionária ao seu vizinho aos danos cau- 
sados. Nesta empreitada, o governo iraquiano decide enviar tropas para ocupar o Kuwait, tomando assim os poços de petróleo. Condenando a invasão e com medo que se alastrasse aos campos de petróleo da Arábia Saudita, a Organização das Nações Unidas (ONU), em prol do Kuwait, solicita uma invasão militar sob a liderança dos EUA junto aos aliados Inglaterra, França, Egito, Síria, Arábia Saudita (Moore et al. s/d).

De acordo com os objetivos estratégicos articulados pelo presidente Bush para a invasão no Golfo Pérsico, esta constava de: libertação do Kuwait e de reféns ocidentais detidos pelo Iraque; defender a Arábia Saudita de uma possível invasão; destruir as armas em massa para assim estabilizar a região (Pagonis e Krase 1992).

Seguindo as instruções dos objetivos estratégicos a nível operacional, pode-se observar que ficou a cargo do comando de apoio logístico (Cmdo Log ou "SUPCOM") apoiar o Corpo de Exército no U. S. Army (Castro 2003). O SUPCOM, por sua vez, está ligado ao Comandante do Teatro de Operações (TO), que atua por meio de apoio de área (Area Support Groups - ASG) multifuncionais ou especializados. A ASG tinha o papel de executar o apoio logístico de suprimentos, serviços de campanha e manutenção, assim como fornecer apoio em transporte e em saúde (Castro 2003).

Com a chegada dos EUA ao TO, foi organizado um comando de apoio logístico, denominado "22nd Support Command” (22nd SUPCOM), subordinado ao Comandante da operação, General Pagonis. Ao 22nd SUPCOM, organizar toda a infraestrutura de apoio às forças ali presentes. Dentre suas missões cabe (Castro 2003):

[...] ajustar, desenvolver e organizar o apoio logístico fornecido pela nação anfitriã às necessidades das forças aliadas; utilizar toda a infraestrutura local para fornecer o apoio logístico, desenvolvendo-a nas áreas onde essa estrutura se apresentava carente; receber as forças aliadas destinadas ao Golfo Pérsico, alojá-las, alimentá-las, e deslocá-las para suas áreas de reunião, proporcionando condições para que pudessem adaptar-se às condições locais, visando ao combate; reduzir os encargos de efetivos militares necessários por meio da contratação de mão de obra civil; estruturar-se valendo-se dos militares recém-chegados ao TO e meios fornecidos pela Arábia Saudita (Castro 2003).

Apesar de todo um alicerce para a operação, as atividades do 22nd SUPCOM foram criadas sob uma estrutura logística subordinada aos XVIII e VII Corpos do Exército, buscando uma visualização mais completa da estrutura logística no TO. 
Assim, após a consolidação da estrutura funcional logística, visando apoiar as operações militares, o 22nd SUPCOM evolui para uma fase operacional, aonde seis fases foram definidas com o objetivo de apoiar as operações: $1^{\mathrm{a}}$ ) preparação e pré-posicionamento; $2^{\mathrm{a}}$ ) deslocamento dos XVIII e VII Corpos de Exército; $3^{\mathrm{a}}$ ) ofensiva terrestre; $4^{\mathrm{a}}$ ) defesa do Kuwait; $5^{\mathrm{a}}$ ) retorno da tropa; e $6^{\mathrm{a}}$ ) reconstrução do Kuwait. Desta forma, bases logísticas foram desdobradas no percurso das estradas principais, de maneira a armazenar e fornecer suprimento à medida que fosse necessário aos XVIII e VII Corpos do Exército (Castro 2003).

Da mesma forma, foi necessário que bases logísticas fossem colocadas em locais estratégicos (em torno do complexo aeroportuário de Dharan, Ad Damman e Jubayl) na Arábia Saudita para receber mais contingentes. Igualmente, com a intenção de projetar poder, foram instaladas bases logísticas provisórias em território iraquiano (Hotel, Golf, Oscar, Romeo e November - vide figura 4), contando também com $101^{\mathrm{a}}$ Divisão Aeromóvel (101st Airborne Division) com o intuito de propiciar ações de grande envergadura e rapidez (Castro 2003).

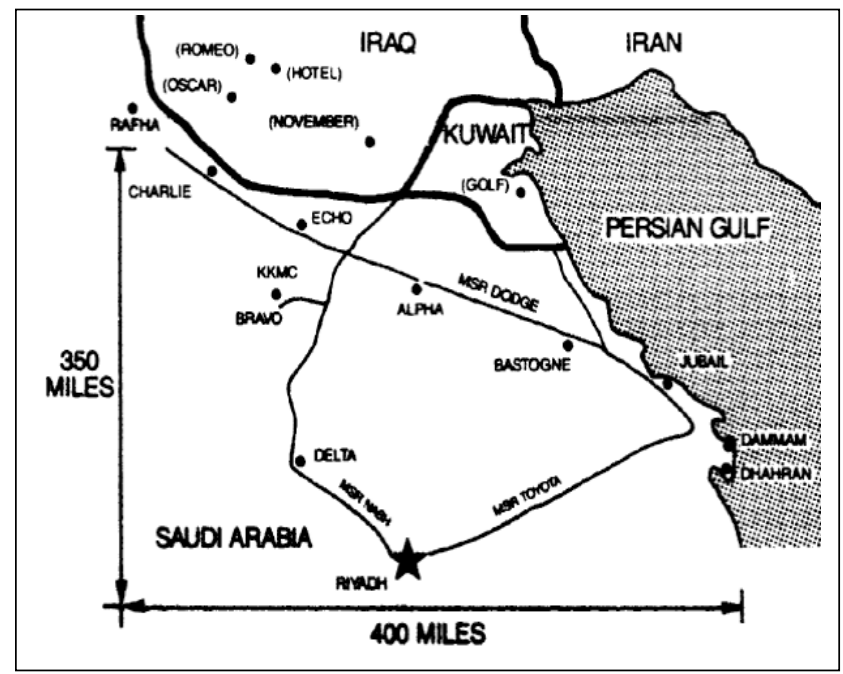

Figura 4 - Mapa do Teatro de Operações e suas Bases Logísticas. Fonte: Pagonis e Krase (1992, 7).

Estas bases puderam contar também com a ajuda de diversos continentes no envio de suprimentos e efetivos, em navios pré-posicionados. Porém, à medida que os Corpos do Exército chegavam, era necessária adaptação 
logística no TO. Constatou-se também que devido a precariedade da infraestrutura local e da insuficiência dos meios orgânicos norte-americanos para o deslocamento das forças no TO, foi necessário o emprego de empresas locais prestadoras de serviços, como empresas comerciais locais e o próprio Sistema de Transporte Público Saudita, e também motoristas de diversas nacionalidades (Castro 2003).

\section{O PAPEL DAS TICS NA LOGÍSTICA MILITAR DA GUERRA DO GOLFO}

Não diferentemente dos demais TO e seus diferentes tipos de ambientes, o deserto encontrado e enfrentado pelos norte-americanos e seus aliados na Guerra do Golfo foi um desafio, tanto pela complexidade quanto pela larga escala. Era diferente e desconhecido do que as tropas estavam acostumadas, o que, além do difícil acesso e escassez, sem a possibilidade de acesso à tecnologia de navegação por satélite, teria tornado a missão "impossível” (Moore et al. s/d).

Diante das dificuldades enfrentadas em campo, com a ajuda das TICs esta operação militar ficou conhecida como "o maior desenvolvimento militar e esforço logístico desde a Segunda Guerra Mundial, seguido pela vitória mais rápida e decisiva de sua escala” (Rottman e Volstad apud Moore et al. s/d). ${ }^{15}$

Foi no uso de equipamentos avançados de navegação por satélite, os GPS (Global Positioning System), que os países da coalizão obtiveram vantagem ante as tropas iraquianas (Moore et al. s/d), através da atualização e informações pertinentes e confiáveis (Kress 2002), onde buscou-se explorar essa vantagem decisiva, no que tange às informações sobre o adversário e no que se refere à tecnologia na capacidade de manobra (Moore et al. s/d).

Os três pontos cruciais apontados na utilidade da informação no TO são: i) alocação adequada de recursos entre unidades militares; ii) determinar a viabilidade da mobilização; e iii) manutenção da cadeia de apoio logístico (Kress 2002). O poder aéreo também foi crucial para o desenvolvimento das operações nas três fases da operação inicial: destruição do sistema de comando e controle do Iraque, isolar o campo de batalha e enfraquecer as forças iraquianas no teatro de operações do Kuwait. Em fevereiro de 1991 as tropas iraquianas foram expulsas do Kuwait. As forças de Saddam Hussein não suportaram os ataques feitos pela coalizão, que utilizaram de tecnologia superior, como o GPS e a logística mencionada, como a sua habilidade em manter uma ofensiva "high-tempo" executada por meio de um planejamento bem realizado, combinando forças aéreas e deslocamento terrestre (Black 2005). Associado com qualidade de combate, coesão das unidades e liderança (elementos que o Iraque possuía em deficiência) esses fatores favorece- 
ram a vitória militar dos americanos (Black 2005, 237). Os estadunidenses empregaram satélites de vigilância, mísseis cruise e bombas guiadas a laser que possibilitaram bombardeios com precisão (Black 2005, 237).

\section{CONSIDERAÇÕES FINAIS}

Ao longo desse trabalho, expusemos a importância da logística para os desdobramentos da guerra. Visivelmente a logística militar se apresenta como grande arcabouço de qualquer operação militar. Quanto maior sua flexibilidade, adaptação e desenvoltura, maiores são as chances de se alcançar os objetivos traçados no primeiro nível logístico, a estratégia logística.

O elemento diretamente ligado às expectativas respaldadas na logística é sem dúvida a economia, esta fornecerá meios para que as capacidades necessárias para o seu desenvolvimento sejam estimuladas. Pois a logística militar demanda além de grandes investimentos uma política prospectiva em longo prazo para sua implementação.

O estudo de caso da Guerra do Golfo (1991) evidenciou o papel das tecnologias de informação e comunicação. Nas guerras subsequentes, como nos Bálcãs, esta demanda torna-se cada vez mais expressiva no ambiente do pós-Guerra Fria, onde o papel das TICs estende-se ao ambiente do teatro de operações militares, como o fator cada vez mais decisivo para a obtenção dos resultados esperados. A disponibilidade deste aparato tecnológico proporciona a flexibilidade logística através de prontas respostas, e uma rápida mobilização devido a informação em tempo real. Por meio de instrumentos como os satélites e a rede de comunicações, as Forças Armadas Americanas atingiram o seu objetivo com eficiência. A Guerra do Golfo trouxe à tona discussões sobre projeção de força, logística (foco do artigo) e interoperabilidade, embora essa última tenha sido facilitada pelas experiências adquiridas em operações conjuntas com a Otan. Como será observado em conflitos durante os anos 1990 e 2000, as TICs associadas a uma logística eficiente serão fatores decisivos para se atingir o ponto de gravidade do inimigo e se alcançar a vitória na guerra.

\section{REFERÊNCIAS}

Alves, V. C. 2010. A Guerra do Golfo. Tensões Mundiais/World Tensions, 6 (10), 191-211.4 Disponível em: <http://www.tensoesmundiais.net/index.php/tm/article/view/166>. Acesso em: 15 set. 2015.

Ballou, R. H. 2004. Gerenciamento da Cadeia de Suprimentos/ Logística Empresarial. 5. ed. [s/l]: Bookman. 
Black, J. 2005. Introduction to Global Military History: 1775 to the present day. Nova Iorque: Routledge.

Brick, E. S. 2011. Base Logística de Defesa: Conceituação, Composição e Dinâmica de Funcionamento. In: V ENCONTRO DA ASSOCIAÇÃO BRASILEIRA DE ESTUDOS DE DEFESA. Fortaleza. Anais... Disponível em: <http://www.defesa. uff.br/images/Textos/Artigos/Base\%20Logstica\%20de\%20Defesa.pdf > . Acesso em: 13 set. 2014 .

Castro, F. B.. 2003. A Logística na Guerra do Golfo. Revista de Segurança e Defesa. Disponível em: <http://www.segurancaedefesa.com/index.php/ artigos/231-a-logistica-na-guerra-do-golfo>. Acesso em: 05 maio 2017.

Clarke, R. A.; Knake, R. K. 2010. Cyber War_the next threat to National Security and What to do About it. [s/l]: Harper Collins E-books.

Council of Supply Chain Management Professionals. S/d. Supply Chain Management/Logistics Management Definitions. Diponível em: <https://cscmp. org/about-us/supply-chain-management-definitions>. Acesso em: 13 set. 2015.

Duarte, É. E. 2012. Conduta da Guerra na Era Digital e suas Implicações para o Brasil: Uma Análise de Conceitos, Políticas e Práticas de Defesa. Brasília/Rio de Janeiro: Instituto de Pesquisa Econômica Aplicada - IPEA.

Estado-Maior do Exército. 2014. Ministério da Defesa do Exército Brasileiro. Exército Brasileiro. Manual de Campanha. Logística. 3. ed. [s/l]: [s/n].

Fox, L. 2008. Defence Logistics Challenges. Defence ViewPoints. Reino Unido. Disponivel em: <http://www.defenceviewpoints.co.uk/defence-industry/defence-logistics-challenges $>$. Acesso em: 27 jun. 2015.

Jomini, B. de. 2005. The Art of War. Texas: El Paso de Norte Press.

Kane, T. M. 2001. Military Logistics and Strategic Performance. University of Hull. Londres: Ed. Routledge.

Kress, M. 2002. Operational Logistics. The Art and Science of Sustaining Military Operations. (PDF). New York: Springer Science+Business Media.

Lamus, L. A. T. 2015. Impacto de las TIC en la Logistica y Movilizaction Militar. Disponível em: <http://documents.tips/documents/las-tic-en-el-ambito-logistico-militar.html>. Acesso em: 15 set. 2015.

Marquardt, K. S. 1999. The Army's Operational Logistics Doctrine For The Twenty-First Century. School of Advanced Military Studies/United States Army 
Command and General Staff College. Disponível em: <http://oai.dtic.mil/oai/oa i? verb $=$ getRecord \&metadataPrefix $=$ html\&identifier $=$ ADA401039 $>$. Acesso em: 28 jun. 2015.

Mark, C. B. 2004. Defence Logistics - The Challenge of Effectiveness and Efficiency. RUSI Defence Systems, 30-31. [s/1]: [s/n].

Ministério da Defesa. 2012. Doutrina de Mobilização Militar (DMM). 1. ed. [s/l]: $[\mathrm{s} / \mathrm{n}]$.

Moore, D. M.; Antill, P. D.; Bradford, J. P. S/d. Logistics Support during the Gulf War. Case 1.6 // Operation Granby.

NAO - The National Audit Office. 2003. About us. Reino Unido. Disponível em: <http://www.nao.org.uk/about-us/\#>. Acesso em: 14 set. 2015.

Nunes, P. F. V. 1999. Impacto das Novas Tecnologias no Meio Militar: A Guerra de Informação. Congresso Internacional da Imprensa Militar. Lisboa, Portugal. Disponível em: <http://www.airpower.maxwell.af.mil/apjinternational/ apj-p/2000/2trioo/nunes.htm>. Acesso em: 15 set. 2015.

Pagonis, W. G.; Krase, M. D. 1992. Operational Logistics and the Gulf War. The Institute for Land Warfare. No. 13, EUA.

Silva, C. A. da; Musetti, M. A. 2003. Logística Militar e Empresarial: Uma Abordagem Reflexiva. R.Adm., São Paulo, 38 (4), 343-354.

Thorpe's, G. C. 1986. Pure Logistics. [s/1]: Ed. NDU Press Publication.

Yoho, K. D.; Rietjens, S.; Tatham, P. 2013. Defence logistics: an important research Field in need of researchers. International Journal of Physical Distribution ${ }^{\circ}$ Logistics Management, 43 (2), 80-96. Disponível em: <http://dx.doi.org/10.1108/ IJPDLM-03-2012-0079>. Acesso em: 25 jun. 2015. 


\section{NOTAS}

1. Original: For want of a nail, the shoe was lost/For want of a shoe, the horse was lost/For want of a horse, the rider was lost/For want of a rider, the battle was lost.

2. Original: An army marches on its stomach.

3. Original: Understand that the [...] foundation of an army is the belly.

4. A Council of Logistics Management Profesionals (CLMP) é uma organização criada para estimular e incentivar os estudos logísticos.

5. Original: Logistics management is that part of supply chain management that plans, implements, and controls the efficient, effective forward and reverses flow and storage of goods, services and related information between the point of origin and the point of consumption in order to meet customers' requirements

6. Logistics is the art of moving armies. It comprises the order and details of marches and camps, and of quartering and supplying troops; in a word, it is the execution of strategic and tactical enterprises

7. As demais ferramentas para condução da guerra, de acordo com Jomini, são: estratégia, a grande tática, a engenharia (de fortificações) e a tática menor (Brick 2011).

8. Original: A multi-dimensional and complex entity that constitutes one of the most important and essential components of warfare.

9. Segundo o glossário do Manual de Doutrina de Mobilização Militar, mobilização nacional trata-se de: um "conjunto de atividades planejadas, orientadas e empreendidas pelo Estado, complementando a Logística Nacional, destinadas a capacitar o País a realizar ações estratégicas no campo da Defesa Nacional, diante de agressão estrangeira” (Ministério da Defesa 2012, 38).

10. Ainda de acordo com o Manual de Doutrina de Mobilização Militar, desmobilização nacional: um "conjunto de atividades planejadas, orientadas e empreendidas pelo Estado, com vistas ao retorno gradativo do País à situação de normalidade, quando cessados ou reduzidos os motivos determinantes da execução da Mobilização Nacional” (Ministério da Defesa 2012, 37).

11. Ainda quanto às similitudes das empresas privadas e da defesa militar na área da logística encontramos pontos como o alto custo x dilema do controle inerente às decisões de terceirização. Por sua vez, quanto aos pontos divergentes pode-se citar que, no campo da logística militar, o fato de enfrentar e atuar em um ambiente operacional onde a infraestrutura física e das comunicações são facilmente danificadas, pode significar perda de indivíduos e possíveis feridos; em contra partida na logística empresarial pode haver perda de lucro ou fechamento da própria empresa (Yoho et al., 2013). 
12. O The National Audit Office (NAO - Gabinete de Auditoria Nacional), localizado no Reino Unido, é um órgão destinado a analisar a despesa pública do Parlamento

13. Original: demands of expeditionary logistics are very different from those that prevailed in the Cold War.

14. Information Warfare. Termo utilizado por Clarke e Knake (2010, 37), em Cyber War the next threat to National Security and What to do About it.

15. Original: the greatest military deployment and logistical effort since World War II, followed by the most rapid and decisive victory of its scale. 


\section{RESUMO}

A Guerra do Golfo (1991) é considerada nas Relações Internacionais como o conflito que inaugurou o pós Guerra Fria. Nos poucos meses que durou o embate, observou-se o uso intensivo de moderna tecnologia militar. $\mathrm{O}$ presente trabalho irá procurar levantar o papel das TICs na logística de defesa.

Palavras-chave: Logística de Defesa; TICs; Pós-Guerra Fria; Guerra do Golfo.

\section{ABSTRACT}

The Gulf War (1991) is considered in International Relations as the conflict that inaugurated the post Cold War. In the few months that the clash lasted, it was observed the intensive use of modern military technology. The present work will seek to raise the role of ICTs in defence logistics.

Keywords: Defence Logistics; ICTs; Post-Cold War; Gulf War. 